\title{
Imagens, foco, hibridização: mais do mesmo na publicidade ${ }^{1}$
}

\author{
Sandra Fischer ${ }^{2}$
}

\section{Resumo}

As imagens que se verificam em campanhas publicitárias de moda e de marcas de roupas cada vez mais tendem à hibridização e ao pretenso desvio de foco, esmaecendo a imagem do produto roupa propriamente dito para enfatizar imagens que carregam conceitos e modos de se dar a ver e de se colocar no mundo específicos e atinentes ao universo identitário com os quais as marcas pretendem se associar. Partindo de tais evidências e à luz de pressupostos teóricos que englobam noções ampliadas de hibridização e o conceito de carnavalização bakhtiniano, este trabalho tem a intenção de desenvolver reflexões para um estudo comparativo entre duas peças integrantes de campanhas veiculadas pelas griffes de roupas e acessórios Forum e Diesel. A hibridização temática e figurativa entre as campanhas e suas conseqüentes inter-relações é o que se pretende explorar neste artigo.

Palavras-chaves: Imagem e hibridização; campanhas publicitárias e identidade; marca Forum e marca Diesel.

\begin{abstract}
Contemporary fashion and clothes griffes publicity campaigns tend both to suffer a process of hybridization and to deviate the focus from their specific products to drive attention and emphasize concepts, identities, attitudes and ways of self-presenting and social performance related to the universe of consumers they intend to be associated with. Based upon these evidences and relying on hybridization notions and on studies developed by Mikhail Bakhtin, this work aims at outlining appointments to a comparative study between two pieces of advertisements that integrate campaigns divulged by the griffes of clothes and accessories Forum and Diesel. The intention is to explore both the thematic and figurative hybridization between the referred campaigns and their consequent interrelations.
\end{abstract}

Keywords: Image and hybridization; publicity campaigns and identity; Forum brand and Diesel brand. 


\section{Imagens da publicidade contemporânea: maisdomesmodemais}

As imagens observáveis nas campanhas publicitárias de moda e de marcas de roupas que vêm sendo veiculadas nos últimos tempos cada vez mais tendem, a exemplo do que há muito já acontece com as campanhas de cigarros e de bebidas, a se revelarem hibridizadas e promotoras de um pretenso desvio de foco. Hibridizadas, na medida em que se interpenetram trazendo à baila e colocando em cena situações, personagens e entrechos narrativos estruturalmente repetitivos ou, ao menos, relativamente próximos e assemelhados - os quais, por vezes, acabam mesmo fusionados; e, ainda, na medida em que se propagam por entre as diversas mídias desdobradas em uma diversidade de formatos - o que faz com que, eventualmente, deixem de se constituir em simples anúncios publicitários para se transformar em espécies de clips, pequenos filmes de curta-metragem, games ou sites interativos. Pseudo-desfocadas - ou pseudo-promotoras de desvio de foco - à medida que, diminuindo a luz sobre o produto que anunciam, buscam enfatizar, não a presença banal de um mero objeto de consumo, mas a evocação de determinados conceitos e modus vivendi que implicam maneiras de se dar a ver e de se colocar no mundo específicos e atinentes aos universos identitários com os quais as marcas pretendem se associar.

De forma indireta, de um lado em virtude da hibridização resultante do "acaso" proporcionado pela intertextualidade que se estabelece no âmbito da publicidade, e de outro pela adoção estratégica da simulação de desvio de foco, esse tipo de campanha, ao contrário do que pode parecer à primeira vista, acaba por vitaminar a figura do produto anunciado e por alargar o espectro de abrangência dos efeitos de sentido decorrentes de sua presença: primeiramente, porque a dita hibridização faz com que seja ampliado e fortalecido, por meio mesmo da transformação (ou da aparente transformação), todo um sistema de redes de consumo sustentado por uma diversidade de sistemas de hábitos e modos de vida - e vice-versa; segundo, porque ao recorrerem, inicialmente, ao recurso manipulatório de fazer crer que o quê menos importa é o apagado e esmaecido objeto em pauta, são campanhas que, ao final das contas, acabam por redirecionar a atenção do comprador potencial para este mesmo objeto: a narrativa subliminar (subliminar?) deixa claro que adquirindo-o, tornando-se o privilegiado senhor de sua posse, o consumidor terá assegurada a possibilidade de acesso ao mundo maravilhoso que contextualiza o tal objeto. A constatação, por parte das marcas e agências de publicidade, da potencial eficiência desse mecanismo de travestimento (no qual luzes de ribalta disfarçadas em sombras de coxias perfazem um movimento de enaltecimento/apagamento) explicaria a proliferação desse tipo de campanha em que o produto parece estar relegado à periferia de um plano secundário.

Partindo das evidências apontadas e com base 1) em noções de hibridização (tomadas em acepção literal e metafórica); 2) no fenômeno migração de imagens e conteúdos nos termos daquilo que Eric Landowski define como atualização de virtualidades; e 3) no conceito de carnavalização proposto por Mikhail 
Bakhtin, este trabalho, inserido no âmbito de uma pesquisa sobre indumentária e identidade, desenvolve algumas reflexões decorrentes de um estudo comparativo entre duas peças integrantes de campanhas publicitárias veiculadas pelas griffes de roupas e acessórios Forum, brasileira, e Diesel, marca de origem italiana.

O que pretendemos neste momento é apresentar reflexões que visam a alicerçar a exploração de aspectos relativos aos seguintes tópicos: $1^{\circ}$ ) o modo como cada uma das marcas se dá a ver e assim define sua imagem e a que tipo de universo identitário e imagético ambas indicam associação; $2^{\circ}$ ) a maneira como se dá a carnavalização das imagens do corpo em ambas as campanhas publicitárias e os decorrentes efeitos de sentido produzidos em termos de construção da imagem da marca; $3^{\circ}$ ) a ocorrência, entre essas campanhas, daquilo que estamos chamando fenômeno de migração de imagens e conteúdos e os conseqüentes efeitos de sentido decorrentes da hibridização resultante - considerando como determinante, no recorte específico, o fato de as campanhas surgirem veiculadas, simultaneamente, em diversas mídias e sob vários formatos, de maneira que o caráter de simples publicidade fica, em certa extensão, diluído ou disfarçado sob a capa de uma espécie de jogo que se estabelece entre as diversas mídias e se articula por meio de imagens impressas, de séries de clips televisivos e/ou pequenos filmes abrigados em sites interativos.

As campanhas publicitárias Forum e Diesel - a primeira intitulada Dona Flor e seus dois maridos e a segunda batizada como Diesel Heaven - ilustram de forma exemplar a lógica desse jogo de separação e fusão, afastamento e aproximação estabelecido pelos entrecruzamentos das redes constituídas pelas manifestações publicitárias. As peças selecionadas remetem uma à outra tanto em termos plásticos, no que diz respeito ao plano da expressão, quanto em termos daquilo que é atinente ao plano do conteúdo narrativo: elas rimam, se interpenetram $^{3}$, o que resulta, objetivamente, no estabelecimento de uma espécie de diálogo, de uma conversa que acaba por atualizar virtualidades.

Com efeito, as imagens da publicidade participariam em conjunto, como explicita Landowski em Presenças do outro (2002, p.136-8), de um mesmo jogo de linguagem, de uma mesma "gramática do olhar" que se caracterizaria tanto pelo "registro figurativo que exploram" como pelo "tipo de sintaxe interacional que utilizam". Decorreria daí a possibilidade de se reconhecer para além da heterogeneidade daquilo que não passaria, em princípio, de um mero e simples conjunto de imagens a "unidade estrutural constitutiva de um gênero determinado" e aí residiria o cerne daquilo que "heuristicamente, nos autoriza a encadear sistematicamente umas com as outras as imagens-ocorrências" que se verificam na publicidade, levando em consideração que qualquer uma dessas imagens "pressupõe todas as demais e adquire sentido por referência a elas, seja, paradigmaticamente, enquanto fórmulas alternativas possíveis no âmbito do gênero considerado". Uma imagem, sobretudo quando é figurativa, assevera Landowski, "sempre convoca para si ao menos uma outra" e "a atualização das virtualidades sugeridas pode se dar também em algum outro espaço, fora do texto ou da imagem". Geralmente, não é necessário procurar muito longe esse espaço de atualização, uma vez que 
“as virtualidades do gênero que um dado anúncio publicitário pode sugerir, outro anúncio, quase sempre, se encarregará de atualizá-las". De acordo com tal ponto de vista, então, um anúncio publicitário sempre anuncia outro anúncio publicitário que por sua vez anuncia outro ainda e assim sucessivamente.

As imagens publicitárias, então, parecem que se pensam e se chamam umas às outras, posto que aquilo que uma toma como pressuposto, sugere ou induz a esperar, criando expectativas, será patentemente manifestado em outra. Dessa maneira, cada imagem como que se transforma na promessa de uma imagem outra, na miragem de algo que, não obstante estar ainda ausente, já é configurável "de modo tal que nosso olhar, contanto que o deixemos se deter, acha-se logo prisioneiro não exatamente daquilo que se mostra, mas da espera de um possível ainda a se atualizar". Vistas por esse ângulo, as diversas imagens da publicidade tanto não se dão a ver de forma isolada, singular, quanto não adquirem valor cada uma em si mesma e por si mesma: interpenetram-se, misturam-se, validam-se; freqüentemente, ainda, as fotos que aparecem em revistas, cartazes, catálogos e afins, são imagens que evocam montagens cinematográficas ou mesmo filmes específicos - como é o caso das imagens que se verificam nas referidas campanhas Forum e Diesel. Os anúncios, assim, não apenas perfazem um vasto, imenso espetáculo ao qual somos convidados a assistir e a aderir, participando diretamente, como também se articulam (bastando para isso, como aponta Landowski, que sejam dispostas e arranjadas em determinados "encadeamentos significativos" as imagens estáticas que "de uma página da revista para outra, ou de um cruzamento da cidade para outro, estão expostas de modo disperso [...] à maneira de peças isoladas que só vêm a adquirir sentido quando contempladas enquanto partes de uma totalidade dinâmica a construir ou reconstituir") e, em certa extensão, acabam sofrendo um processo de hibridização.

\section{Forum no paraíso movido a Diesel e vice-versa}

A campanha da marca brasileira Forum para o verão 2004 acompanhou e explorou o tema da coleção, inspirada na obra literária Dona Flor e seus dois maridos, de Jorge Amado; veiculada por meio da mídia impressa, em jornais e revistas, de outdoors espalhados pelas ruas de algumas capitais e de painéis fotográficos colocados em vitrines de lojas Forum, a campanha é composta de várias peças em que fragmentos textuais do livro de Amado são apresentados de maneira a interagir com fotos coloridas de J. R. Duran que exibem a personagem Dona Flor - protagonista na narrativa do livro e na da campanha, e nesta última representada por modelo jovem e sensual - focalizada sozinha ou desfrutando da companhia de seus dois maridos.

Também divulgada em suportes diversos, tais como no site da marca, outdoors, totens em corredores de shopping-centers e revistas de moda, a campanha outono/inverno 2006 da marca italiana Diesel consiste de várias peças em que fotos coloridas, de autoria de Terry Richardson, apresentam jovens modelos - todos eles esguios e de aspecto andrógino - portando enormes asas brancas, caracterizados como se fossem anjos. Em 
poses sempre provocantes e sugestivamente eróticas, exibidos sozinhos ou acompanhados de outros modelos igualmente jovens, os "anjos" (que ocupam no universo narrativo estabelecido pela campanha o lugar central destinado ao protagonista) lançam olhares pouco ou mesmo nada angelicais em direção ao destinatário ou a seus companheiros de foto.

No que diz respeito à campanha publicitária da Forum, trabalhamos com aspectos atinentes ao segmento que foi veiculado no jornal Folha de S. Paulo. Durante oito dias seguidos a campanha, cujo tom foi definido por meio do jogo que se articula entre o visual e o textual, abre o caderno Folha Ilustrada; a série é dividida em diversas peças que, ocupando praticamente a íntegra da página, deixam espaço apenas para headlines que anunciam temas cujo teor, direta ou indiretamente, acaba apresentando algum tipo de relação com a foto situada logo abaixo delas. Introduzidas à moda de espetáculo, "Forum apresenta: Dona Flor e seus dois maridos", as peças compõem uma narrativa, construída por meio de fotos provocantes aliadas a picantes passagens da obra do escritor baiano. A seleção de textos e a composição das fotos relatam a essência da saga de Dona Flor aludindo enfaticamente às experiências sexuais vivenciadas pela protagonista. A estrutura e o desenvolvimento narrativos da campanha seguem as linhas mestras do livro: as peças giram em torno das ambigüidades que caracterizam a figura, a composição psicológica e a performance da personagem principal. Seu eixo fundamental, no entanto, consiste na inversão do papel da protagonista, tal qual se configura explicitamente na peça exibida no dia $1^{\circ}$ de setembro de 2003 , que encerra a série publicitária veiculada no jornal apresentando, emblematicamente, a versão imagética da campanha e o fragmento do romance a ela correspondente: Dona Flor caminha ladeada por seus dois maridos, a bolinar o traseiro de ambos; tem o rosto voltado para o destinatário, a quem dirige uma piscadela cúmplice. Em destaque, ao lado direito do quadro, o logotipo da marca: a letra $\mathbf{F}$ maiúscula, branca, inserida dentro do espaço vazado de um losango formado por linhas brancas; ao lado do logotipo, em caixa alta, corpo cheio, letras brancas, a palavra FORUM; sustentando Forum, em letras menores, de cor vermelha, caixa alta e corpo fino, uma escritura: DESEJO DO BRASIL. É esta a peça que nos interessou particularmente. 


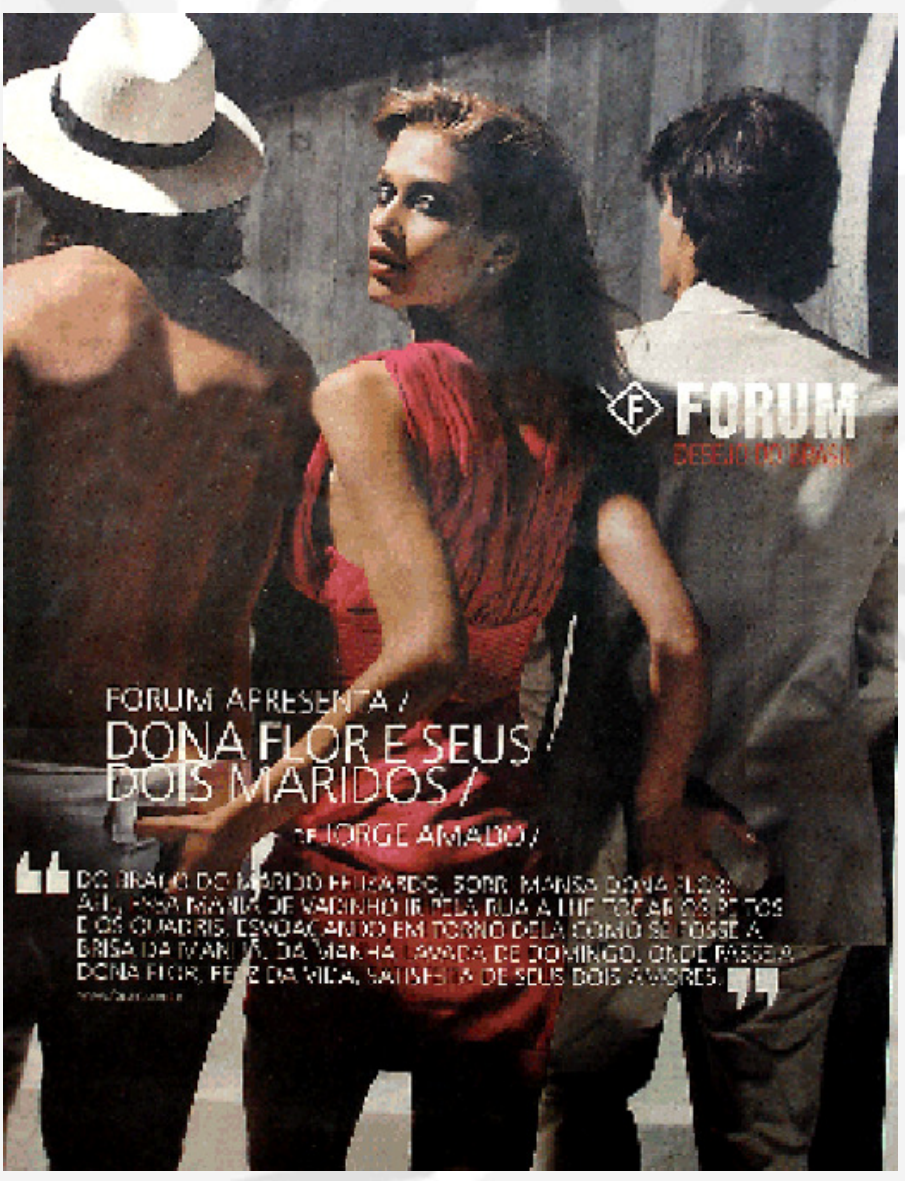

No que se refere à campanha da marca Diesel, a ênfase de nosso trabalho recaiu especificamente sobre a peça que veiculou imagens em que o modelo caracterizado como anjo está ladeado por dois outros modelos um deles masculino, cabelos curtos, e o outro, que ostenta longos cabelos lisos, feminino -, todos os três retratados de costas para o destinatário. $\mathrm{O}$ anjo de cabelos encaracolados e curtos exibe as asas no torso nu e tem os quadris cobertos por uma faixa de tecido branco; seus vizinhos vestem ambos calças jeans, camisa de mangas curtas o rapaz e camiseta sem mangas a garota. Sobre o dorso de ambos estendem-se as asas do anjo, a abraçá-los e encobri-los parcialmente. A mão da jovem repousa espalmada sobre a anca direita do querubim, o qual tem a cabeça levemente inclinada e o rosto virado na direção do rosto dela; os lábios estão sensualmente entreabertos, de forma a denotar que ele estaria dizendo - quase sussurrando, talvez - algo à companheira. Ao fundo, um céu em que se misturam sombras de massas plúmbeas e luzes de nuvens brancas banhadas e perpassadas por raios solares reforça, por meio do claro-escuro que domina a cena, a atmosfera de ambigüidade já sugerida pela figura do anjo. O grupo, que se encontra em pé sobre as nuvens, parece prestes a iniciar uma caminhada rumo ao horizonte celestial que se lhe estende à frente. 


\section{DIESEL}

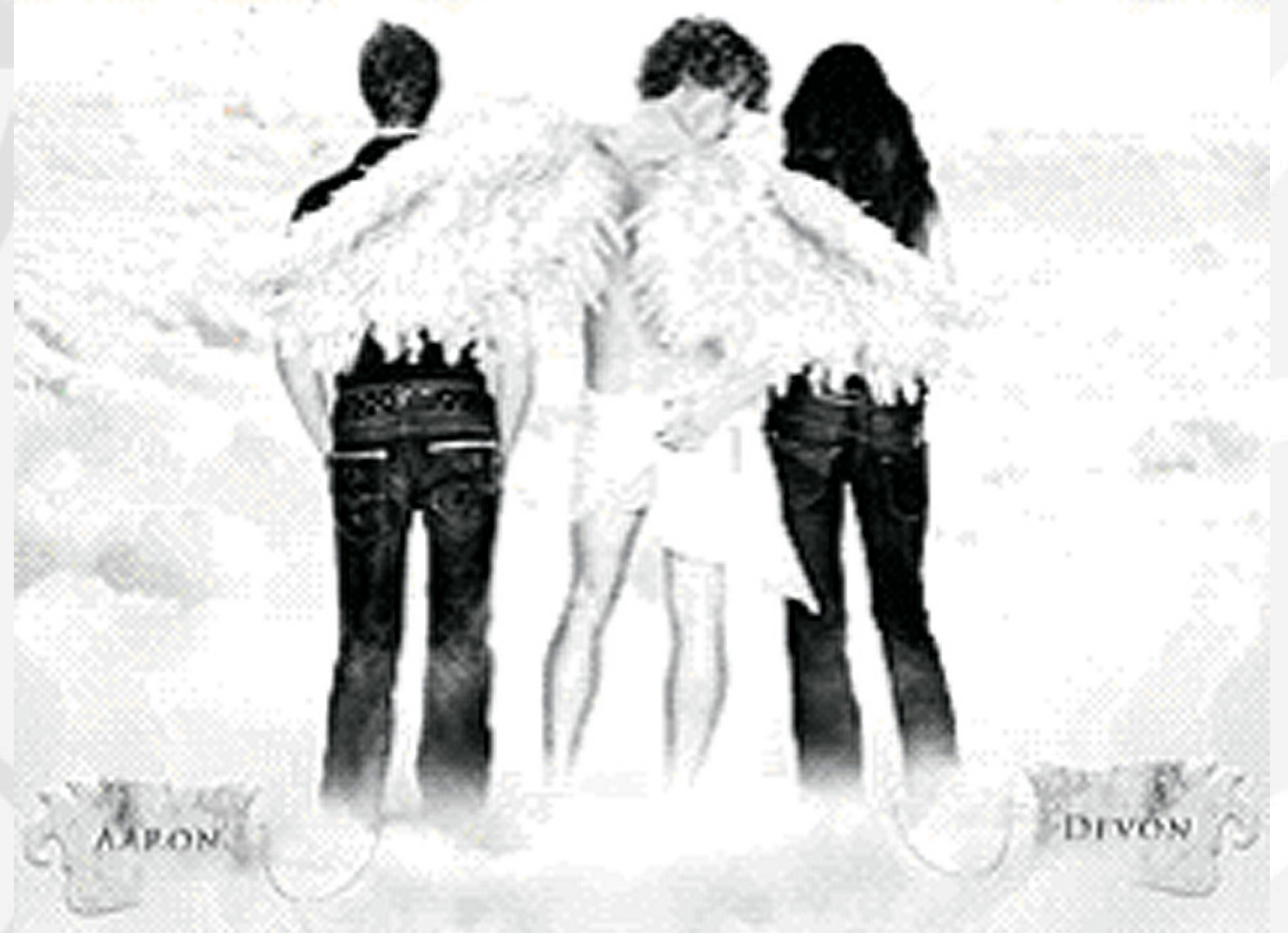

No canto superior direito do quadro, um retângulo vermelho com o nome DIESEL grafado em letras brancas maiúsculas apóia-se sobre a inscrição "for successful living"; na altura dos pés dos modelos que ladeiam o anjo, duas inscrições: AARON na lateral esquerda do menino e $\operatorname{DEVON}^{4}$ na lateral direita da menina. Diferentemente daquilo que acontece na foto da Forum, na qual a combinação imagem/texto sugere que o grupo que passeia na manhã de domingo dirige-se rumo a um porvir de prazer e felicidade, desta vez a foto tende a intrigar e a suscitar indagações: o horizonte que se configura frente ao trio é nebuloso. Quais 
seriam exatamente suas promessas? Gozo, susto, ventura ou desventura? Mistério e incerteza convenientemente instigantes: no mínimo, prenunciam descobertas e possibilidades de sensações inusitadas. De que espécie de paraíso trata, afinal, esta campanha denominada "Diesel Heaven" se o slogan da marca fala em "successful living"? Um paraíso onírico, situado nas nuvens, em alguma dimensão entre o céu e a terra? E quanto ao anjo, estaria ele prestes a conduzir os dois jovens que se alinham a seu lado, a julgar pela posição das asas abertas sobre ambos, para as maravilhas insuspeitadas de um éden inusitado? Ou seriam eles dois sensuais e sedutores - a conduzir esse anjo caído de volta ao paraíso perdido e revisitado ou, ainda, rumo a um outro tipo de nirvana, inédito e peculiar?

O hibridismo que se pode observar entre as campanhas - resultante das proximidades imagéticofigurativas, plásticas e temáticas - e suas conseqüentes inter-relações em termos de imagens e conceitos que orientam e dimensionam as identidades e os modos de se dar a ver de cada uma das marcas é o que, especialmente, nos chamou a atenção. No caso da primeira, interessou-nos sobremaneira analisar as conseqüências plásticas e semânticas da intensa imbricação de relações híbridas que estabelece entre o perfil da marca que anuncia e o caráter da obra literária e de suas versões para o cinema, em filme de Bruno Barreto, e para a televisão, em mini-série vinculada ao Núcleo Guel Arraes da Rede Globo de Televisão ${ }^{5}$. No caso da segunda, dedicamo-nos particularmente a identificar, ressaltar e examinar as relações de hibridização verificáveis entre ela e a primeira e a analisar as conseqüências daí advindas.

Em sua totalidade, a campanha Forum remete, como já dissemos, ao livro de Jorge Amado, Dona Flor e seus dois maridos, e também ao filme e à minissérie homônimos; hibridiza e carnavaliza todas as galáxias em que se inspira - e intensifica tanto essa hibridização quanto essa carnavalização na peça final da série publicitária, quando apresenta uma sua Dona Flor muito peculiar, atualizada, assumindo atitudes que não necessariamente seriam parte do repertório de competências da personagem original, mas sim da competência de uma Dona flor renovada, uma personagem que transcende os limites da diegese de Jorge Amado: uma mulher de receitas outras, dissociada da domesticidade de panelas e fogões, inserida na contemporaneidade, urbana e consumidora.

Por meio de um fragmento particular - a referida peça do anjo ladeado por dois jovens - a campanha Diesel parece, se não se inspirar, ao menos dialogar com todos esses universos aludidos e/ou configurados pela campanha Forum, ou seja: a marca não apenas sugere saber (termo aqui empregado em seu sentido ambíguo, que remete a conhecimento e a sabor) do Brasil como tende a fazer crer que pode ir além disso - na medida em que, de certa maneira, apresenta o universo ("macro") da Diesel englobando o universo ("micro") da Forum, carregando para seu interior algo daquilo que é Forum, misturando essa porção Forum com o que ali há de Diesel e hibridizando tais imagens. Por intermédio dessa peça em particular Diesel insinua entender do paradisíaco e carnavalizado universo brasileiro sugerido pela campanha da Forum - cuja protagonista subversiva, inspirada na perspectiva da receita da heroína de Jorge Amado, garante o paraíso do atendimento 
simultâneo a seus desejos da carne e do espírito reunindo em seu cotidiano um marido indômito e devasso (dedicado ao corpo, ao lúdico, ao prazer, ao delírio) e um marido centrado, responsável e socialmente bem aceito (pragmático, sério, cônscio de seus deveres, instruído e refinado). Sinaliza, ainda, que tal entendimento se dá de maneira competente o suficiente para ir ainda mais longe: o prazer sensual prometido pelo slogan da Forum (desejo de Brasil) e de sua Dona Flor com seus dois maridos está contido, de certa forma, nas formas e atitudes provocativas do anjo e de seus companheiros, na medida em que, topologicamente, as três figuras do anúncio Diesel rimam perfeitamente com as três figuras do anúncio Forum; esse prazer seria, então, ampliado em Diesel - marca que teria sido específica e apropriadamente desenhada for successful life, para a possibilidade (ou mesmo para a certeza) de se alcançar o sucesso e suas conseqüentes benesses. Em tal planeta os anjos, em sua androginia, não só efetivamente se presentificam com asas e tudo, como carnavalizam e subvertem o clima de santidade e placidez usualmente associado à idéia de paraíso. Com tal procedimento, acenam com a multiplicação das possibilidades do prazer prometido: o desejo será enriquecido, maximizado e atendido além das expectativas. Diesel transcende a Forum e a muito mais simplesmente porque é Diesel.

$\mathrm{O}$ anúncio busca reforçar, dessa forma reverberativa, o que o já assegura o site da marca: existe um "Diesel universe", um cosmos muito próprio e restrito, ao qual apenas os consumidores potenciais - um punhado de seres desejantes iluminados e privilegiados, detentores das especiais condições que habilitam tal seleto grupo a adquirir produtos Diesel - podem ter acesso. Sejam tais seres italianos, brasileiros ou de qualquer nacionalidade. Sejam homens, mulheres, anjos, demônios. Ou um misto disso tudo, enfim, um híbrido. O que os define e identifica, em última análise e ad eternum, é consumir Diesel sobre todas as coisas.

Entre o que se aloja em entrelinhas e em entre-imagens, o substrato de um subtexto: Forum, "excelente", é Brasil; Diesel, por sua vez, o supra-sumo da "excelência", é mundo. Dado isto tudo, não conviria, talvez - insinua o enunciador a seu enunciatário potencial -, experimentar, trocar a Forum pela Diesel? Há muito de Forum em Diesel, dá a entender a campanha. Diesel contém Forum, posto que a suposta brasilidade típica, no anúncio Forum indicada, entre outros elementos, pelo regionalismo do romance de Jorge Amado, pela morenice da pele e pela sensualidade das formas de Dona Flor e de seus dois maridos, na foto do anúncio Diesel estaria recuperada e presentificada tanto na compleição física e nas poses ostentadas pelo anjo e por seus companheiros quanto na disposição figurativa, na colocação do grupo em cena. Trata-se então, afinal, de um produto de origem européia, uma espécie de imposição vinda do exterior, de algo puramente estrangeiro ao Brasil da Forum tropical, ou de algo que poderia ser também considerado como nosso - ao menos enquanto opção de escolha e conseqüente assunção (parcial ou total) de identidade? Será Diesel, italiana simplesmente, ou será Diesel complexa, enriquecida, posto que acrescida de uma brasilidade sofisticada, graça concedida a uns poucos escolhidos? Serão criaturas anjos ou serão criaturas humanas, as figuras da foto? Femininas ou masculinas? Personagens literárias, cinematográficas, modelos, atores? Onde uns, onde outros? E, sobretudo, o que é este anúncio, afinal, o que são estas imagens? Fragmentos de campanhas publicitárias, partes refeitas de 
um filme, algum tipo complexo de entretenimento? Ou um cúmplice, um passaporte para o múltiplo - o jogo, a sedução, o romance, a transgressão, o sucesso - implicado na maravilhosa viagem do consumo? Onde os limites, enfim?

Misturada, hibridizada, re-focada, a imagem do objeto, do produto anunciado, adquire, aí, um valor de téssera: a senha para se adentrar ao prometido universo de imagens outras, ou seja, aquelas que contextualizam o objeto, que lhe servem de estojo, relicário, santuário. Objeto não perdido e nem esquecido, afinal, posto que ali está, onipresente peça de roupa ou acessório pronto para ser atualizado, colocado em ato. Objeto-valor que, uma vez adquirido, é capaz de garantir poder, vitória, bem-aventurança, a obtenção de tudo o que interessa e importa. Então, rumo a ser aquele que É, um ser compra. 


\section{Referências bibliográficas}

AMADO, Jorge. Dona Flor e seus dois maridos. Rio de Janeiro: Record, 1995.

BAKHTIN, Mikhail. Problemas da poética de Dostoiévski. Rio de Janeiro: Forense Universitária, 1997.

BAKHTIN, Mikhail. A cultura popular na Idade Média e no Renascimento: o contexto de François Rabelais.

São Paulo: Hucitec; Brasília: Editora da Universidade de Brasília, 1999.

BARTHES, Roland. O prazer do texto. São Paulo: Perspectiva, 1987.

BARTHES, Roland. Inéditos, vol. 3: imagem e moda. São Paulo: Martins Fontes, 2005.

BAUDRILLARD, Jean. "Significação da publicidade". In: ADORNO, Theodor W. et ali. Teoria da cultura de massa. Rio de Janeiro: Paz e Terra, 2002.

BELLOUR, Raymond. Entre-imagens. Campinas: Papirus, 1997.

CANCLINI, Nestor Garcia. Culturas híbridas. São Paulo: Edusp, 2000.

FIORIN, José Luiz. As astúcias da enunciação. São Paulo: Ática, 2001.

FISCHER, Sandra. "O apelo do entre: publicidade, desejo e consumo”. In: Significação - revista brasileira de semiótica, nº 24, dez. São Paulo: Annablume, 2005.

FLOCH, Jean-Marie. “Alguns conceitos fundamentais em semiótica geral”. In: Documentos de estudo do Centro de Pesquisas Sociossemióticas, 1. São Paulo: Edições CPS, 2001.

GREIMAS, Algirdas Julian e COURTÉS, Joseph. Dicionário de semiótica. São Paulo: Cultrix, S/D.

LANDOWSKI, Eric. A sociedade refletida. São Paulo: EDUC/Pontes, 1992.

LANDOWSKI, Eric. Presenças do outro. São Paulo: Perspectiva, 2002.

MESQUITA FILHO, Odilon P. (2005) “Nacib e Gabriela ou hibridação entre moderno e pré-moderno”. In:

Graphos - Revista da Pós-Graduação em Letras - UFPB João Pessoa, Vol 7., N. 2/1, 2005 - p. 155-160.

NASCIMENTO, Geraldo Carlos do. A intertextualidade em atos de comunicação. São Paulo: Annablume, 2006.

OLIVEIRA, Ana Claudia de. "Por uma semiótica da moda". In: CASTILHO, K. e GALVÃO, D. A moda do corpo, o corpo da moda. São Paulo: Esfera, 2002.

OLIVEIRA, Ana Claudia de. (Org.) Semiótica plástica. São Paulo: Hacker Editores, 2004.

\footnotetext{
1 Partes deste artigo foram apresentadas no Atelier "Corpo, moda e consumo”, vinculado ao CPS - Centro de Pesquisas Sociossemióticas (Pontifícia Universidade Católica de São Paulo - PUC/SP: Programa de Pós-graduação em Comunicação e Semiótica / USP: Faculdade de Filosofia, Letras e Ciências Humanas / CNRS: Fondation Nationale des Sciences Politiques) 2007, e no $3^{\circ}$ Colóquio de Moda, na Faculdade CIMO - Centro Integrado de Moda, Belo Horizonte (MG), 2007.

2 Doutora em Ciências da Comunicação pela Escola de Comunicações e Artes-ECA da Universidade de São Paulo-USP. Pesquisadora e docente do Programa de Mestrado em Comunicação e Linguagens da Universidade Tuiuti do Paraná-UTP.
} 


\begin{abstract}
${ }^{3}$ Há que notar, todavia, que se por um lado os respectivos repertórios e universos identitários das duas marcas estariam interagindo e interpenetrando-se na diversidade de seus modos de se dar a ver (ambos são anúncios que remetem a roupas de qualidade, destinadas a serem oferecidas a um segmento de compradores jovens, situados nas faixas das classes alta e média-alta; o público alvo idealizado por ambas as marcas tende a ser moderno e instruído, a comungar alguns valores e a caracterizar-se por ser ou julgar-se ser detentor de posturas e atitudes que traduzem algum arrojo e um certo desdém pelas convenções, etc.), por outro lado não deixam de sinalizar diferenças, sutis ou nem tanto, que indicam particularidades e compromissos distintos, singulares, muito próprios de cada griffe.

${ }^{4}$ As palavras Diesel (tipo de combustível, assim denominado em virtude de Rudolf Diesel, engenheiro alemão inventor do motor), Aaron (patriarca dos sacerdotes judeus; montanhês; luz da montanha) e Devon (deriva do nome de tribo celta Dumnonii, algo como "Deep Valley Dwellers") têm seus significados inter-relacionados no entrecho narrativo da campanha: remetem a noções de poder, ascensão, inventividade, mobilidade e renovação.
\end{abstract}

${ }^{5}$ A esse respeito ver artigo intitulado "O apelo do entre: publicidade, desejo e consumo" (FISCHER, 2005). 